\title{
Effects of water stress on relative water, chlorophylls and proline contents in barley (Hordeum vulgare L.) leaves
}

\author{
Foued Chéour ${ }^{1}$, Imène Kaddachi ${ }^{2}$, Dhouha Achouri ${ }^{2}$, \\ Samia Bannour ${ }^{1}$ and Lazhar Zorgui ${ }^{1}$ \\ ${ }^{I}$ Institute of Applied Biology of Médenine, Tunisia \\ ${ }^{2}$ Faculty of Sciences of Bizerte, Tunisia
}

\begin{abstract}
Under both natural and agricultural conditions, plants are often exposed to various environmental stresses. Water stress and drought are the most important environmental factors inhibiting photosynthesis and decreasing growth and productivity of plants. To evaluate the effects of water stress on the physicochemical composition of barley, Tunisian cultivar Ardhaoui, several assays were performed on the leaves such as relative water, chlorophylls and proline contents. Our study showed that the water restriction affected significantly the physicochemical composition of barley leaves. In fact, plants which were subjected to the water stress, showed lower relative water and chlorophylls contents and higher level of proline, compared to the control.
\end{abstract}

Keywords: Water stress, barley, leaves, relative water, chlorophylls, proline

\section{Introduction}

Definition of water stress. Water stress is one of the most important environmental stresses affecting agricultural productivity worldwide (Boyer, 1982). It occupies and will continue to occupy an important place in the agro-business news. It is a serious problem in many arid and semi-arid regions, where precipitations change from year to year and where plants are subjected to more or less long periods of water deficit (Boyer, 1982). There are many definitions of water stress. In agriculture, it is defined as a marked deficit and taking into account the rainfall that significantly reduce agricultural production compared to normal range for a region with a large area. Indeed, there is water stress when demand for water exceeds the available amount during a certain period or when poor quality restricts its use. Water stress causes deterioration of fresh water resources in terms of quantity (groundwater overexploitation, dry rivers...) and quality (eutrophication, organic matter pollution, saline intrusion ...). Water stress may be defined as the ratio between the amount of water required for the growth of the plant and the available water in its environment, whereby the useful reserve of water for the plant is the amount of water soil accessible by its root system (Laperche, 2004). Water stress is any fluid restriction resulting in a lower potential of the plant due to a disturbance of its physiological activity caused by a deficiency of water consumption (Mouhouche and Boulassel, 1997).

Effects of water stress on plant metabolism. Under water stress, a decrease in chlorophylls content was noticed in durum wheat (Triticum durum L.) (Bousba et al., 2009). To reduce water loss by evaporation and also the increase in input resistance of atmospheric $\mathrm{CO}_{2}$ for photosynthesis, water saving results in a relative turgidity less affected by stress leading to a dilution of chlorophylls (Slayter, 1974). The chlorophylls ratio (a/b) is a good indicator of tolerance to water stress (Budak et al., 2013). Tahri et al. (1997) showed that the increase of the foliar proline content under the effect of stress is followed by a decrease in total levels of chlorophylls pigments. According to Bllinger and Lahrer (1987), increased proline content is a protective response of plants against all factors which cause a reduction in the amount of water in cytoplasm. According to these same authors, the synthesis of proline may be involved in the regulation of cytoplasmic $\mathrm{pH}$, it allows the stabilization of membrane proteins and protein-free, hence its osmoprotectant role. The rapid catabolism of proline during stress provides reduced radicals needed in phosphorylation reactions in the mitochondria therefore production of ATP required for the recovery of damages caused by water stress (Cronic, 2000).

The aim of this study is to evaluate the effects of water stress on the physicochemical composition of barley leaves, cultivar Ardhaoui, in the region of Médenine, Tunisia. The parameters tested are relative water, chlorophylls and proline.

\section{Plant material}

\section{Materials and methods}

This study was conducted on barley (Hordeum vulgare L.), cultivar Ardhaoui. This cultivar is grown in Southern Tunisia. It is characterized by its resistance to drought. 


\section{Experimental site and barley cultivation}

The experimental work was performed in the Institute of Arid Regions (IRA) of Médenine, Tunisia. This region is located in the semi-arid bioclimatic stage characterized by low annual rainfall $(150 \mathrm{~mm} / \mathrm{year})$, relatively high temperatures and frequent winds. The soil of the experimental plot is characterized by a sandy texture. The soil consists of $85 \%$ of sand, $5 \%$ of clay and $10 \%$ of silt and it has a low organic content $(<8 \mathrm{~g} / \mathrm{kg})$. The experimental plot is equipped with an irrigation system drip. Irrigation water used comes from a well near the experimental site. During our study, three water regimes were tested whose field capacities were $100 \%\left(\mathrm{R}_{0}\right)$, $60 \%\left(\mathrm{R}_{1}\right)$ or $30 \%\left(\mathrm{R}_{2}\right)$. Barley seeds were planted manually in rows with spacing of $50 \mathrm{~cm}$. The space between plants is of $5 \mathrm{~cm}$. Each elementary plot has 7 lines. The spacing between the elementary plots is $0.8 \mathrm{~m}$. To highlight the adaptation's potential of barley to drought; water stress was induced by the application of a water stress treatment in favourable conditions. After harvesting, the leaves are kept to be analyzed.

\section{Physicochemical analyses of leaves}

Relative water content. The relative moisture content was determined by subtracting the dry weight from the fresh weight. The blade is cut into small squares, then weighed to determine the fresh weight (FW) and then placed in a Petri dish at $5^{\circ} \mathrm{C}$. After 24 hours, the leaf pieces are removed and weighed to determine the turgor weight (TW). Thereafter, they are placed in an oven at $75^{\circ} \mathrm{C}$ for 24 hours and then weighed again to determine the dry weight (DW). The relative water content $(\mathrm{RWC})$ is determined by the formula: $\mathrm{RWC}=(\mathrm{FW}-\mathrm{DW} / \mathrm{TW}-$ DW) x 100 .

Chlorophylls content. The chlorophylls content was determined thanks to a device called SPAD (Reis et al., 2009).

Proline content. Proline was extracted and assayed mainly by the method of Bates et al. (1973). Proline is extracted with 3\% aqueoux sulfosalicylic acid. The lyophilized material volume ratio of extraction is $14 \mathrm{mg} / 1.5$ $\mathrm{ml}$. After centrifugation at $14000 \mathrm{rpm}$ for 10 minutes, the supernatant is recovered and the pellet was resuspended in $1.5 \mathrm{ml}$ of sulfosalicylic acid. The reaction is initiated by adding $1 \mathrm{ml}$ of the extract, $1 \mathrm{ml}$ of ninhydrin and $1 \mathrm{ml}$ of glacial acetic acid. The resulting solution is boiled in a water bath at $100^{\circ} \mathrm{C}$ for one hour. After cooling, $2 \mathrm{ml}$ of toluene was added. After vigorous homogenization, two phases are obtained. The upper phase is recovered and its absorbance is determined thanks to a spectrophotometer at $520 \mathrm{~nm}$.

\section{Data analysis}

The analysis of variance (ANOVA) of results was made following a randomly complete block design (Snedecor and Cochran, 1957) by the GLM procedure of the SAS statistical package (SAS Institute, 1989). Homogeneity of variance was verified by the standard Bartlett test (Anderson and McLean, 1974). Each treatment was replicated six times.

\section{Results}

Although the study was carried out over two consecutive years, the results were similar and only the results of $2^{\text {nd }}$ year were reported. We evaluated the relative amounts of water in mature leaves of barley (Hordeum vulgare L.), cultivar Ardhaoui. Similarly, we measured their concentrations on chlorophylls and on proline.

Figure 1 illustrates the influence of irrigation in the relative amounts of water on barley leaves. Based on these results, the more the amount of water available to most of the cereal increases wetting of the leaves would be significantly $(\mathrm{P} \leq 0.001)$. Thus, barley having been subjected to a water regime of $100 \%$ has accumulated more water in its leaves during production. This effect seems to be independent of the stage of development of the grain $(\mathrm{P} \geq 0.05)$. The accumulation of water in the leaves seems to be increasingly important at the stage of plants flowering and this is irrespective of the irrigation scheme recommended $(\mathrm{P} \leq 0.001)$.

Figure 2 shows the concentrations of chlorophylls in barley leave receiving water regimes of 30,60 and $100 \%$. Chlorophylls levels increased significantly with increasing level of selected irrigation ( $\mathrm{P} \leq 0.001)$. In contrast to chlorophylls, proline contents increased significantly in the leaves gradually as the water regime becomes severe ( $\mathrm{P} \leq 0.001$; Figure 3$)$. In fact, regardless of the stage of development of barley, the proline level in the leaves increases if the irrigation level decreases $(\mathrm{P} \leq 0.001)$. Thus, a water regime of $30 \%$ of field capacity, barley seems to accumulate more proline at its leaves. The accumulation of this amino acid in the leaves of stressed plants began in the 3-leaf stage. 


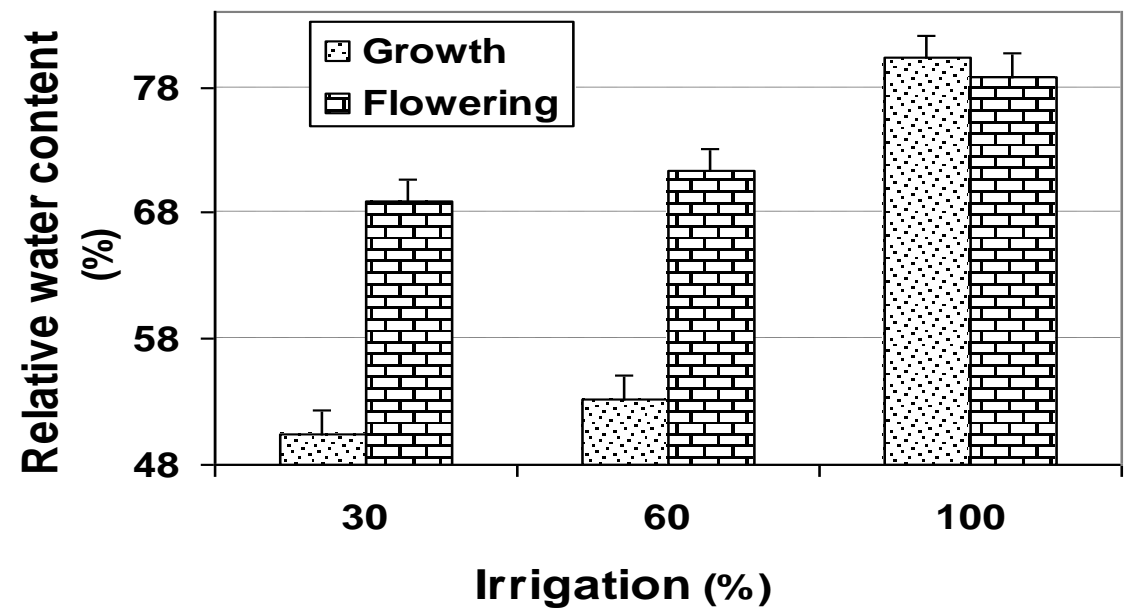

Figure 1. Relative water content in barley leaves, cultivar Ardhaoui, submitted to water regime of 30, 60 or $100 \%$ of field capacity. Vertical bar show average \pm SD for six replicates.

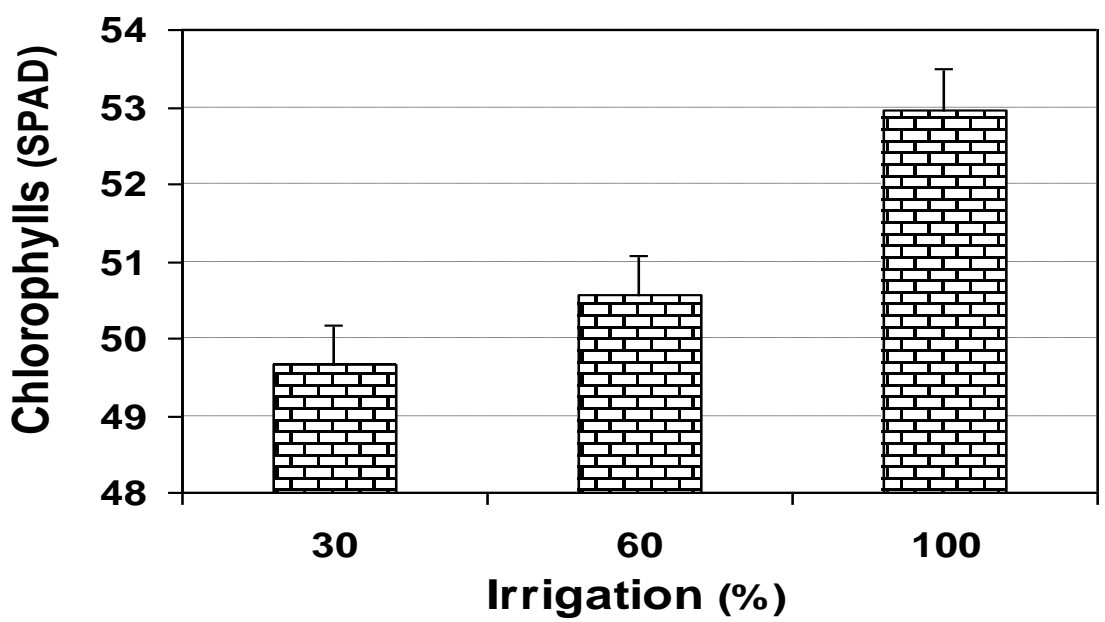

Figure 2. Relative chlorophylls content in barley leaves, cultivar Ardhaoui, submitted to water regime of 30, 60 or $100 \%$ of field capacity. Vertical bar show average \pm SD for six replicates.

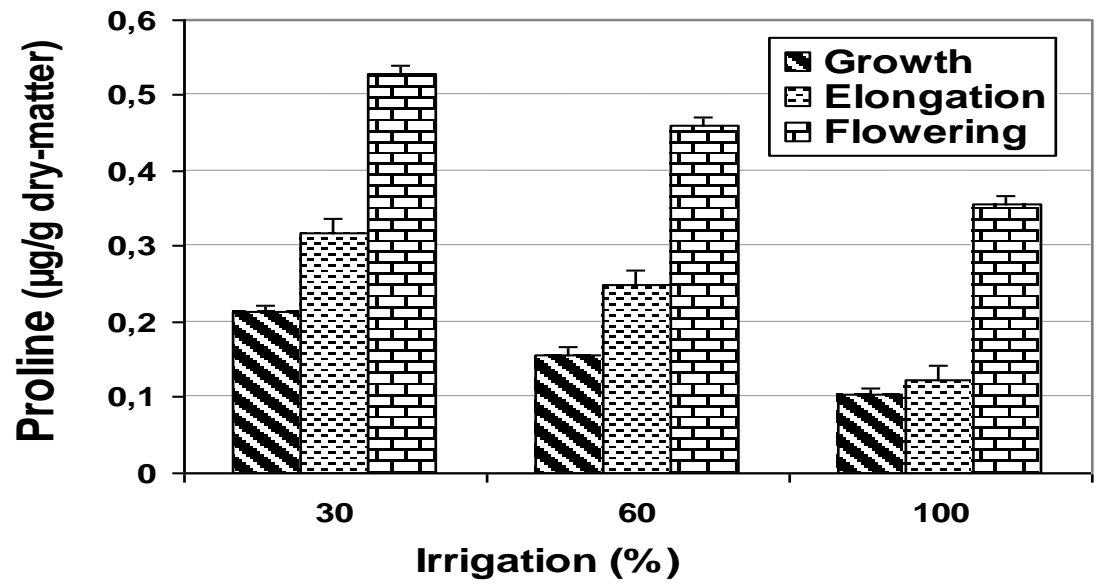

Figure 3. Proline content in barley leaves, cultivar Ardhaoui, submitted to water regime of 30, 60 or $100 \%$ of field capacity. Vertical bar show average \pm SD for six replicates. 


\section{Discussion}

The plant survival under different conditions involves acclimatization and adaptation (Savé et al., 1995). Barley has an ability to withstand drought. The barley resistance results in tolerance mechanisms or osmotic adjustment.

Our study showed that the moisture content decreased significantly in the leaves of plants subjected to water stress. Water is an essential element in crop production especially in arid and semi-arid regions. A reduction in its availability in stressed plants induces a decrease of relative water content (Tsimilli et al., 1998). Thus, the water content of the leaves during our study decreased proportionately with the reduction of the amount of water contained in the soil. Madhava et al. (2006) reported that the relative water content in leaves is an indicator of plant water status under stress.

Our study showed that reducing the level of water availability for plants in production has led to decreases in the synthesis of chlorophylls pigments, substances essential for photosynthesis. This drop in chlorophylls content could be the result of the reduction of stomatal aperture to limit water loss through evapotranspiration and increased resistance to the input of atmospheric $\mathrm{CO}_{2}$ for photosynthesis and/or the increasing the proline production in the leaves (Bousba et al., 2009). Indeed, we showed an increase in the synthesis of proline in barley based on levels of water stress imposed. Such results have been reported in bean and olive (Bllinger and Lahrer, 1987).

During water stress, most of the plants decrease their osmotic potential by accumulation of osmolytes such as inorganic ions, proline, soluble sugars, organic acids..., which allows them to limit evapotranspiration and accentuate the water absorption from the soil. Osmotic adjustment is usually a coping mechanism in response to water stress including several osmolytes which are directly involved (Gluten and Eris, 2004).

Accumulation of proline, an osmoprotectant which is one of the first manifestations of water stress in plants, in the leaves has resulted in a reduction in chlorophylls content in the leaves of barley. Indeed, it is clear that the main precursor of these secondary metabolites is none other than glutamate (Talat et al., 2013). Thereby increasing the synthesis of proline in plants submitted to water stress only accelerate and to ensure their protection. This process not only reduces the synthesis of chlorophylls knowing that the majority of glutamate reserves are diverted towards the synthesis of proline.

\section{Conclusion}

The submission of barley to water stress has significantly influenced the chemical composition of leaves. First, it promoted to the synthesis of proline, an osmoprotectant amino acid and which often plays an essential role in maintaining turgor in plant cells exposed to drought. Also, stress has reduced their chlorophylls concentrations, essential photosynthetic pigments. Leaves from barley plants subjected to water stress also showed moisture levels relatively low in comparison to those that were well-watered.

\section{References}

[1]. Anderson V.L., McLean R.A. 1974. Design of experiments. Marcel Decker, N.Y.

[2]. Bates L.S., Waldren, Teare I.D. 1973. Rapid determination of free proline for water stress studies. Plant soil, 39:205-207.

[3]. Bllinger Y., Lahrer F. 1987. Proline accumulation in higher plants: a redox buffer? Plant physiol., 6:23-27.

[4]. Bousba R., Ykhlef N., Djekoun A. 2009. Water use efficiency and flag leaf photosynthetic in response to water deficit od durum wheat (Triticum durum Desf.). World J. Agri.Sci., 5: 609-616.

[5]. Boyer J.S, 1982. Plant productivity and environment. Sci, New series, 218:443-448.

[6]. Cronic G. 2000. Drought stress inhibits photosynthesis by decreasing stomatal aperture not by effecting ATP. Synth. Trends Sci., 5:187-188.

[7]. Gluten H., Eris A. 2004. Effect of heat stress on peroxidase activity and total protein content in strawberry plants. Plant Sci., 166:739-744.

[8]. Budak H., Kantar M., Kurtoglu K.Y. 2013. Drought Tolerance in Modern and Wild Wheat. Sci. Worl J. Review article. 16p.

[9]. Laperche J.C. 2004. La nutrition de la plante en Biologie végétale. Dunod. $2^{\text {ème }}$ édition; Paris. Pp. 154-163.

[10]. Madhava Rao K.V. Raghavendra A.S., Janardhan Reddy K., 2006. Printed in the Netherlands. Physiology and Molecular Biology of Stress Tolerance in Plants. Springer. Pp. 1-14.

[11]. Mouhouche B., Boulassel A. 1997. Gestion rationnelle des irrigations des compléments des cultures de légumineuses alimentaires et céréales. Recherche Agronomique. INRA, 1:21-31.

[12]. Reis A.R., Favarin J.L., Malavolta E., Lavres J., Moraes F. 2009. Photosynthesis, chlorophylls, and SPAD readings in coffee leaves in relation to nitrogen supply. Comm. Soil Sci. Plant Anal., 40: 1512-1528.

[13]. SAS (Statistical Analysis System). 1982. SAS users guide: Statistics. SAS Institute, Inc., Cary, N.C.

[14]. Savé R., Biel C., Domingo R., Ruiz-Sanchez M.C., Torrecillas A. 1995. Some physiological and morphological characteristics of citrus plants for drought resistance. Plant Sci., 110:167-172.

[15]. Slayter R. 1974. The effect of internal water status on plant growth development and yield in plant responses to climatic factors. Proc. of upsal symposium, UNESCO.

[16]. Snedecor G.W., Cochran W.G. 1957. Statistical methods. 6th ed. Iowa State Univ. Press.

[17]. Tahri E., Belabed A., Sadki K.1997. Effet d'un stress osmotique sur l'accumulation de proline, de chlorophylle et des ARNm codant pour la glutamine synthétase chez trois variétés de blé dur (Triticum durum Desf.). Bulletin de l'Istitut Scientifique. Rebat, 21: 81-89.

[18]. Talat A., Khalid N., Khalid H., Bhatti K.H. 2013. Foliar application of proline for salt tolerance of two wheat (Triticum aestivum L.) cultivars. World Appl. Sci. J., 22: 547-554.

[19]. Tsimilli-Michael M.M., Pêcheux R.J., Strasser F. 1998. Vitality and stress adaptation of the symbionts of coral reef and temperate foraminifers probed in hospite by the fluorescence kinetics O-J-I-P. Archs. Sci. Genève. 51:205-240. 